\title{
ATO I, ATO II
}

ACT I, ACT II

Guilherme Moreira

Guilherme Moreira é fotógrafo, pesquisa narrativas visuais em fotolivros e atua junto ao corpo editorial da Steidl Verlag em Göttingen, Alemanha.

guilhermepessin@gmail.com 
ATO 1 


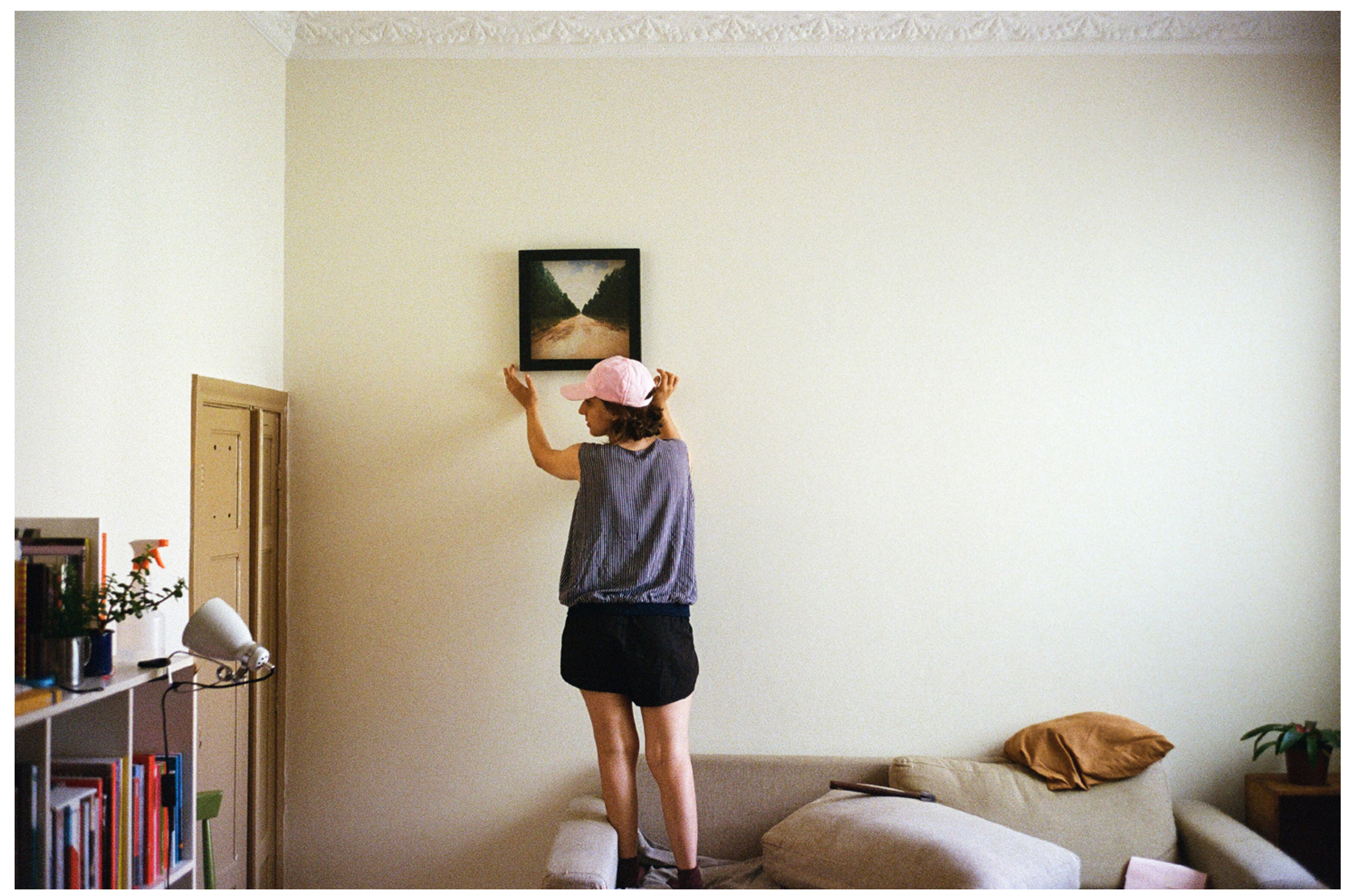




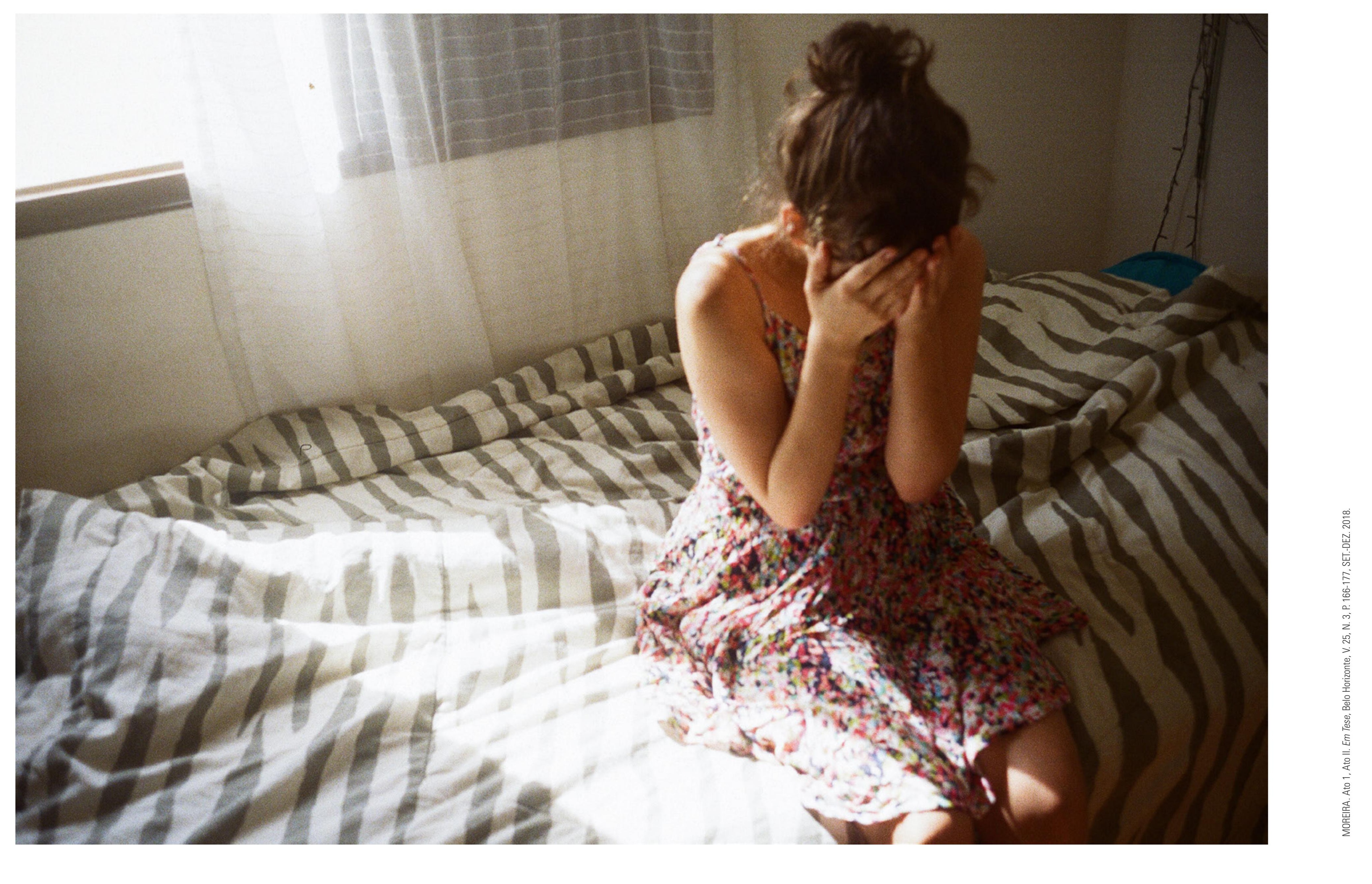




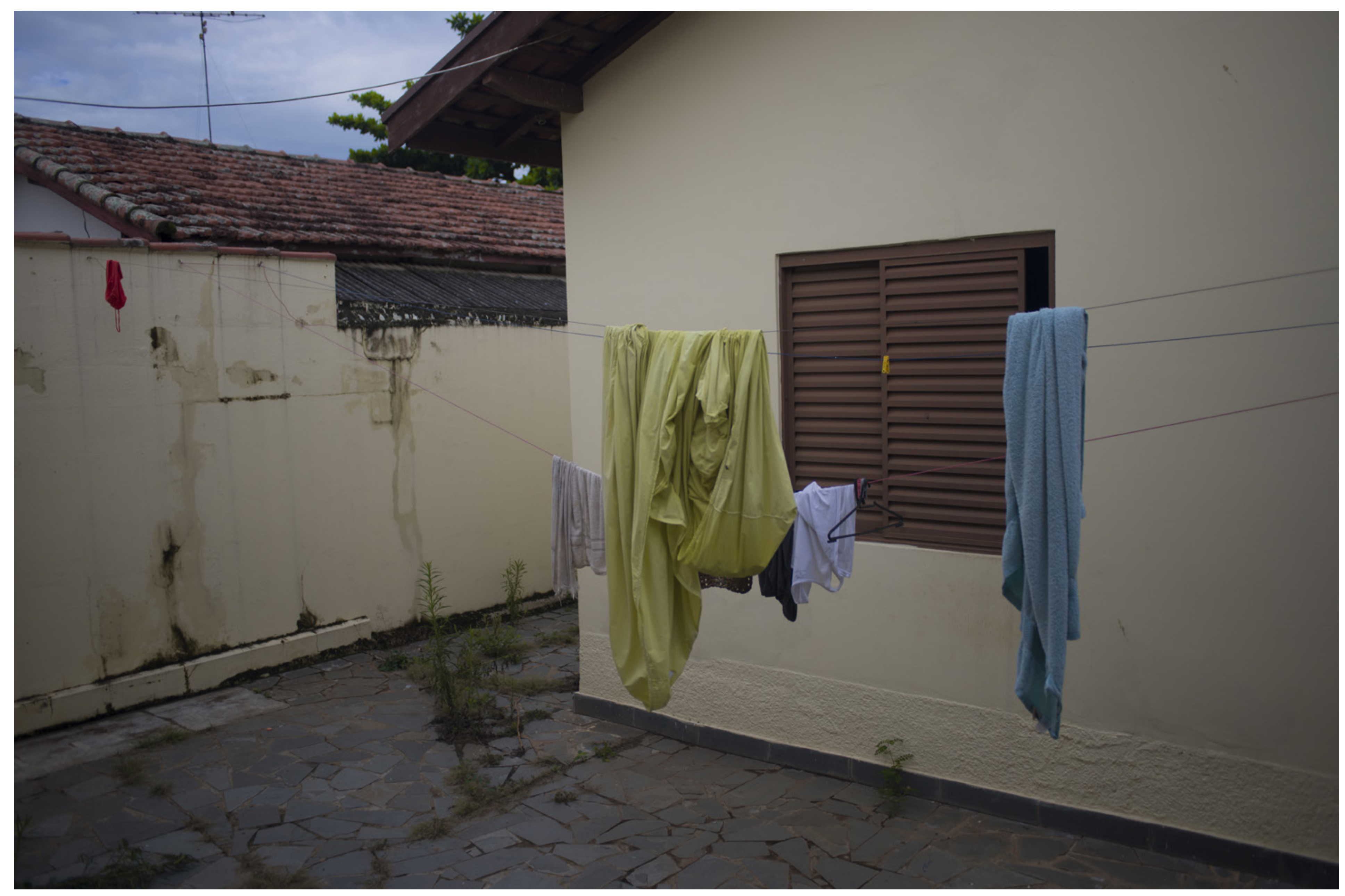




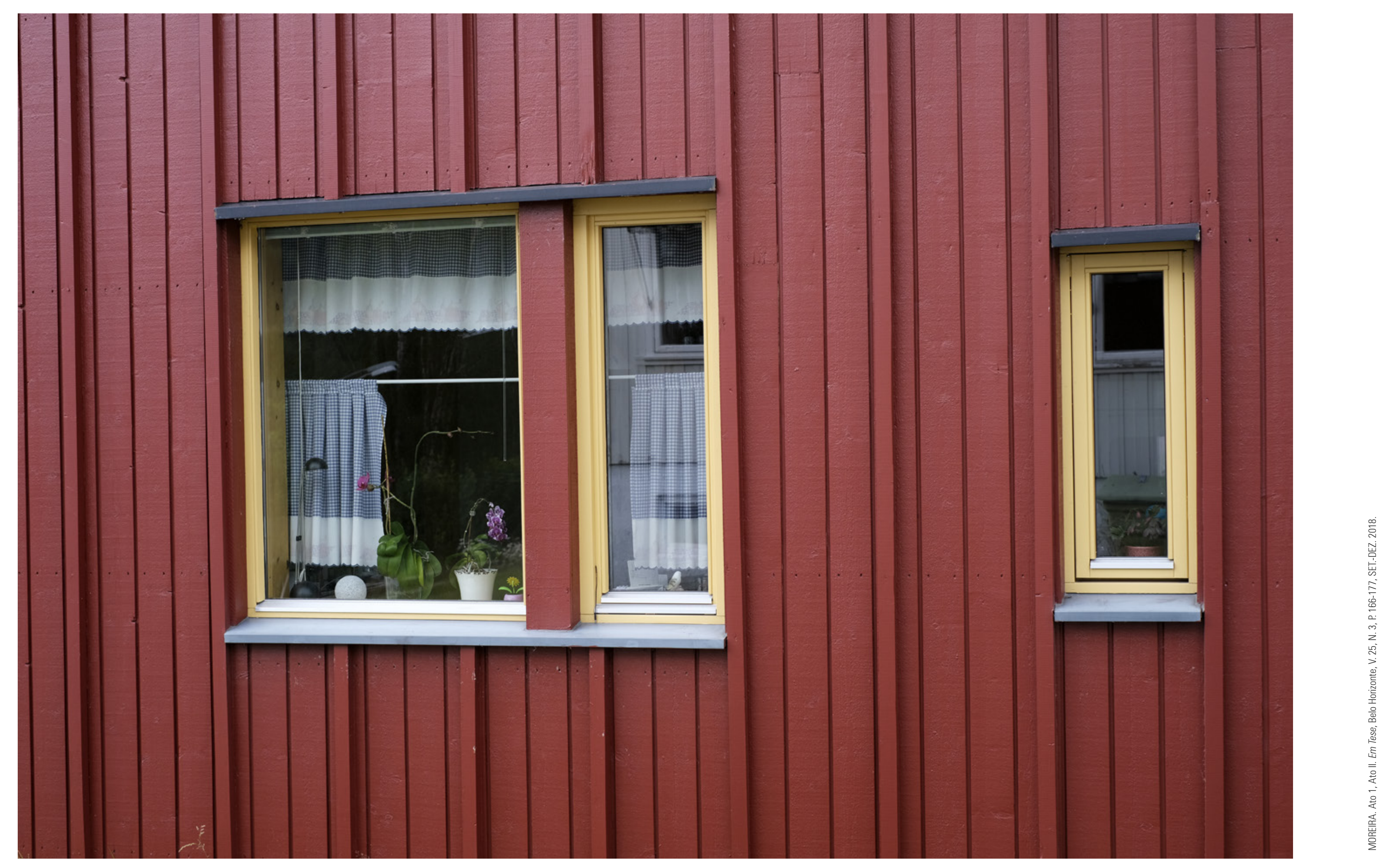


ATO II 


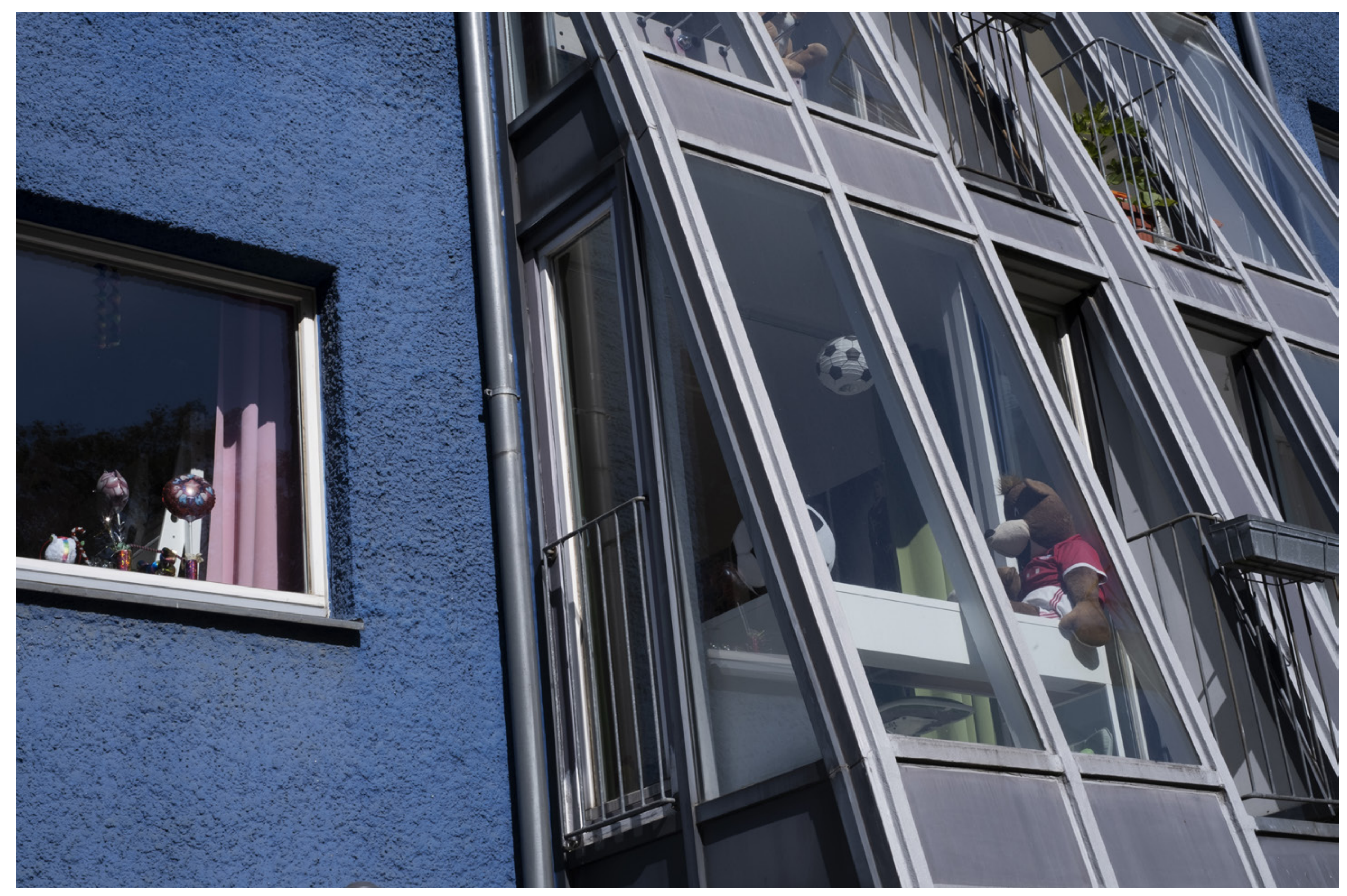




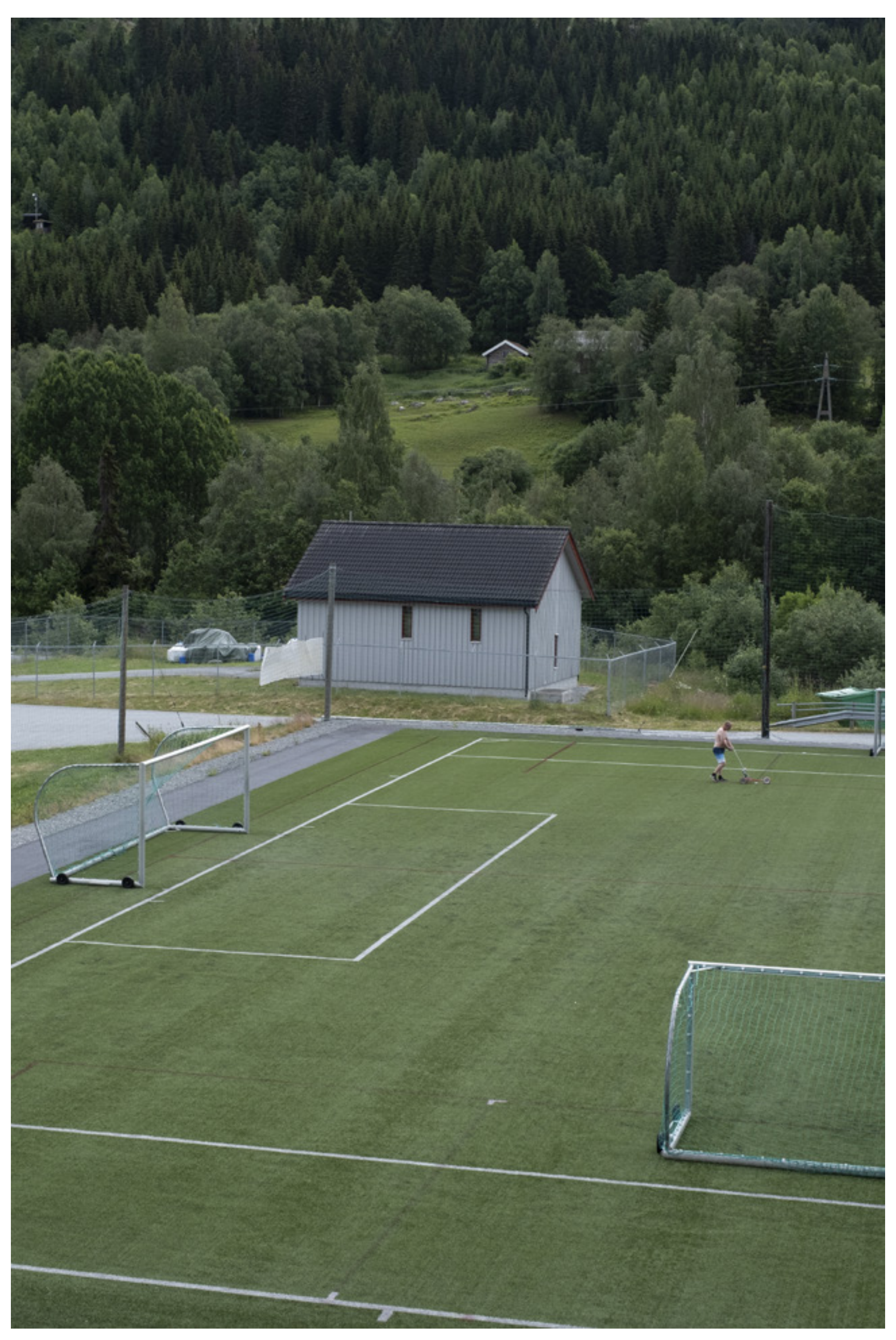




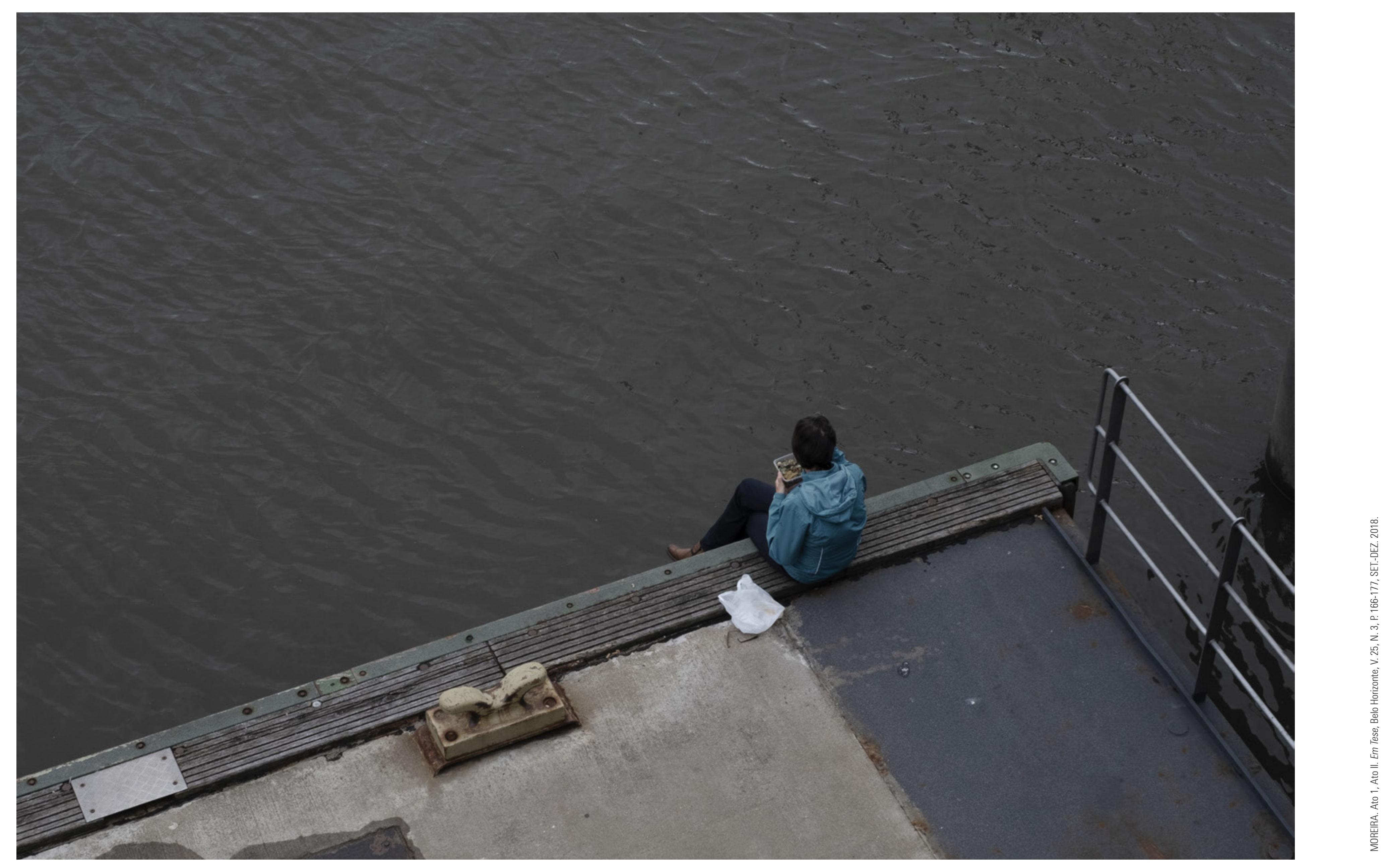




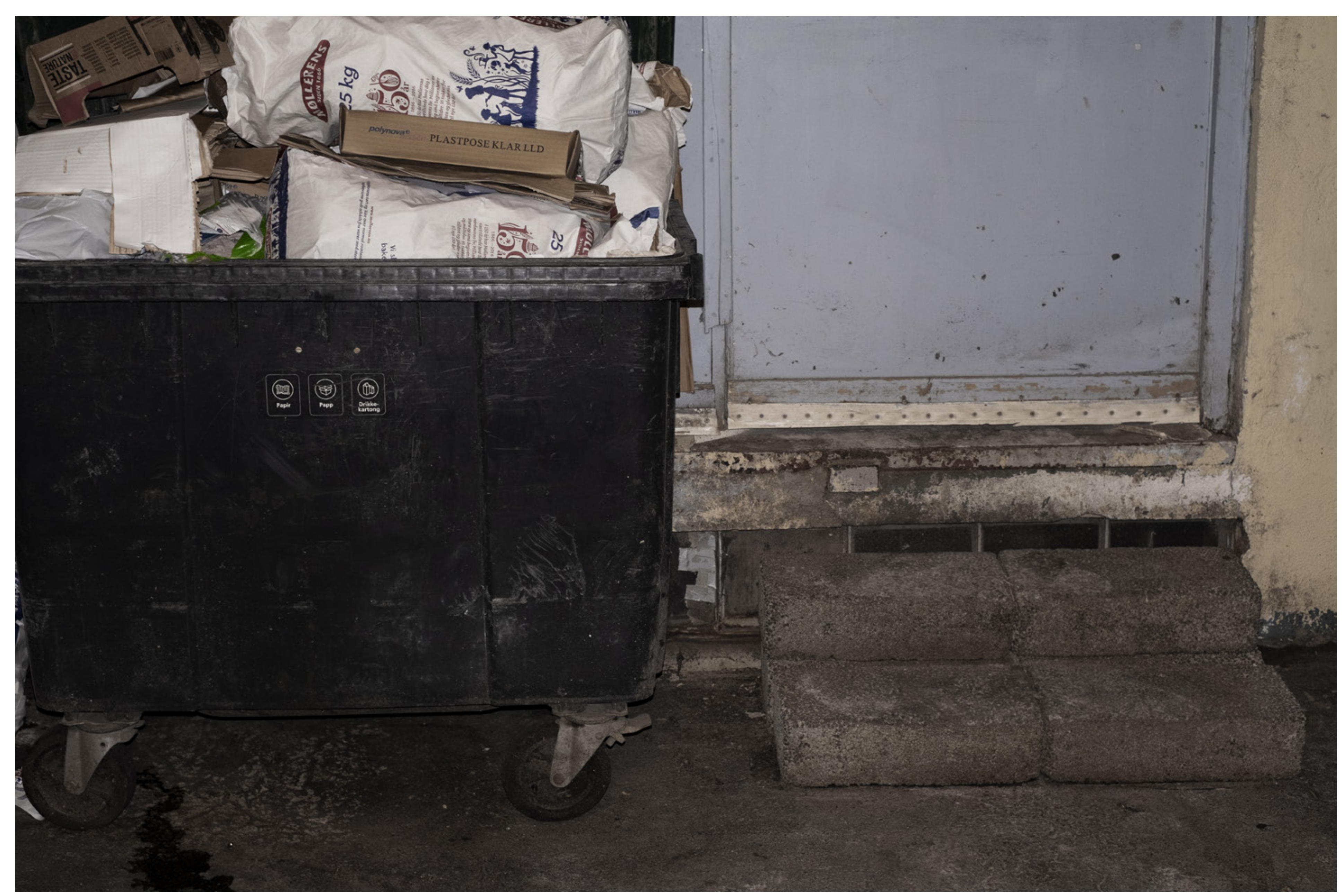

